\title{
Dimethylisosorbide (DMI) as a bio-derived solvent for Pd-catalysed cross-coupling reactions
}

\author{
Kirsty L. Wilson ${ }^{\text {a }}$ \\ Jane Murray ${ }^{b}$ \\ Helen Sneddon ${ }^{c}$ \\ Craig Jamieson ${ }^{a}$ \\ Allan J. B. Watson*d \\ ${ }^{a}$ Department of Pure and Applied Chemistry, University of \\ Strathclyde, Thomas Graham Building, 295 Cathedral Street, \\ Glasgow, G1 1XL, UK. \\ ${ }^{\mathrm{b}}$ Merck KGaA, Frankfurter Straße 250, 64293 Darmstadt, Germany. \\ ' Green Chemistry Performance Unit, GlaxoSmithKline, Medicines \\ Research Centre, Gunnels Wood Road, Stevenage, Hertfordshire, \\ SG1 2NY, UK. \\ ${ }^{d}$ EastChem, School of Chemistry, University of St Andrews, North \\ Haugh, St Andrews, KY16 9ST, UK. \\ * Corresponding author aw260@st-andrews.ac.uk
}

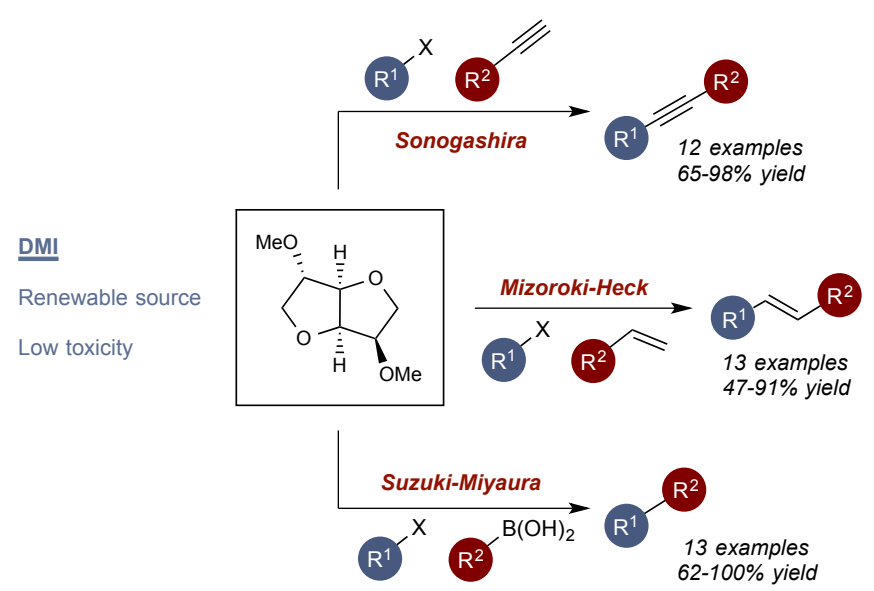

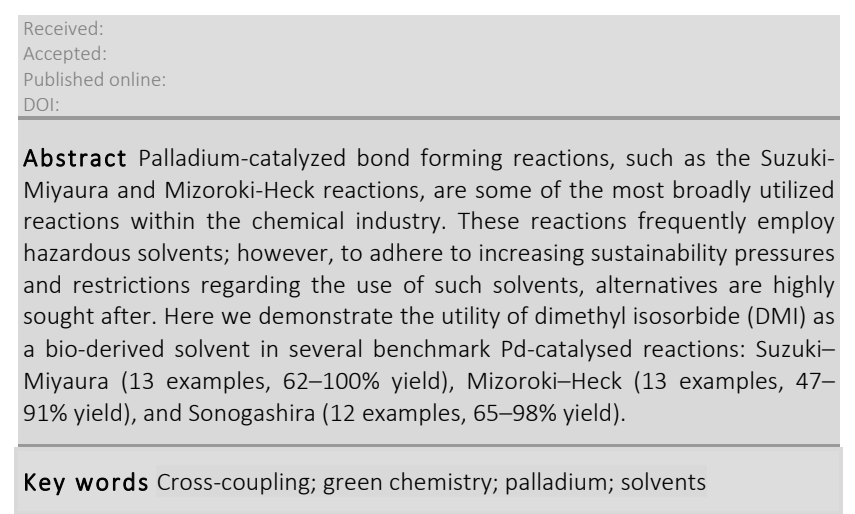

Continuing endeavours by leading industrial companies and academic groups place solvent replacement strategies at the forefront of green chemistry initiatives. The search for alternative solvents is, in part, driven by health, safety, and environmental issues regarding the use of solvents of concern.1-6 For example, dipolar aprotic solvents such as DMF and NMP are teratogenic, whilst 1,4-dioxane is carcinogenic. As such, these solvents, in addition to many others, have fallen under strict regulation.

Subsequently, solvent selection has become a key focus within the pharmaceutical sector, with many groups developing tools and methods to rank existing solvents based on risks posed or favourable physical properties. ${ }^{7-13}$ These guides allow the end user to assess and adjust their reaction manifold by aiding in the identification of a suitable solvent alternative which adheres to best practice in safety guidelines and regulation. ${ }^{14,15}$ Despite these efforts, direct substitution can be challenging particularly with dipolar aprotics. The unique physical properties of these solvents make them indispensable to practitioners and, as such, novel alternatives are required.

The use of biomass feedstocks in the development of new chemical products is a growing area within Green Chemistry, aiming to minimise dependence on petroleum-based chemicals and overall environmental impact of the chemical industries. ${ }^{16-23}$ However the uptake of neoteric solvents can often be slow when application is underexplored. Some recent examples of the applications of new solvents include studies on $\gamma$-valerolactone and Cyrene ${ }^{\mathrm{TM}} .24-34$

Derived from glucose via the platform molecule sorbitol, (Figure 1), dimethyl isosorbide (DMI) has found application in the formulation of cosmetics and pharmaceuticals. ${ }^{35-38}$ Despite displaying similar Hansen solubility parameters (HSP) ${ }^{39}$ to traditional dipolar aprotic solvents and some promising investigations into the use of DMI within amide bond formation, ${ }^{40,41}$ its broader application within organic synthesis, in particular transition metal catalysis, is underdeveloped. Herein we report the use of DMI as a viable alternative to solvents of concern within key C-C bond forming reactions widely used in synthetic organic chemistry.

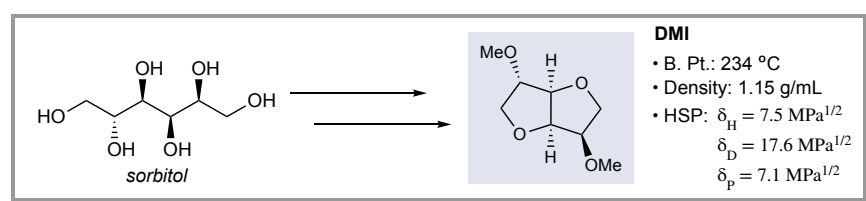

Figure 1 Sorbitol as the platform molecule in the synthesis of DMI.

Palladium-catalysed bond forming reactions are an important tool within the pharmaceutical arena and are often key steps in the syntheses of modern drug compounds 
(Figure 2).42-46 Reactions such as the Suzuki-Miyaura (SM) ${ }^{47,48}$ and Mizoroki-Heck (MH), ${ }^{49}$ allow for late stage derivatisation and divergent syntheses from readily available materials, and the Sonogashira reaction facilitates the installation of an internal alkyne, 50 a versatile functional group and important intermediate for subsequent elaboration. The robustness of these transformations often relies on the use of solvents of concern. THF and 1,4-dioxane are common solvents used for the SM reaction whilst DMF is the traditional medium within the Sonogashira reaction. ${ }^{51}$

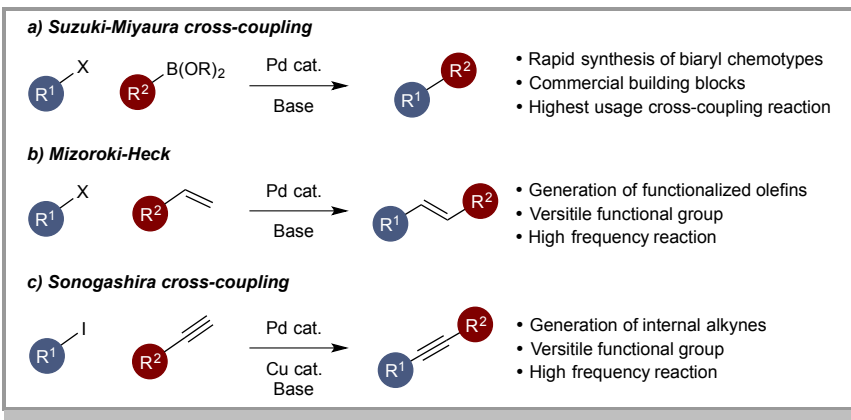

Figure 2 The most common cross-coupling reactions in pharma.

Our aim was to assess whether DMI was viable as a medium for these most common cross-coupling processes. We began our investigations by assessing the utility of DMI within the SM cross-coupling of phenylboronic acid and $p$ bromotoluene (Table 1). Using conditions established within our laboratories, 52 an initial temperature screen demonstrated that the coupling could be carried out with high conversions at $40{ }^{\circ} \mathrm{C}$ in $1 \mathrm{~h}$ (Entry 2). Additionally, the catalyst loading could be reduced to as low as $1 \mathrm{~mol} \%$ before any significant erosion of conversion was observed.

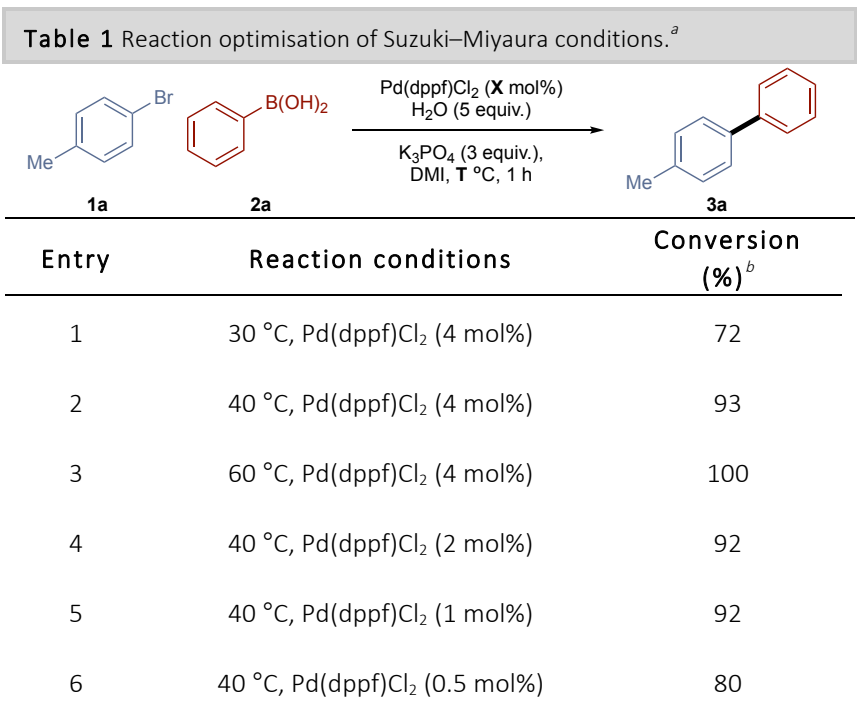

${ }^{a} 4$-Bromotoluene (1 equiv., $0.25 \mathrm{mmol}$ ), phenylboronic acid (1 equiv., 0.25 mmol), $\mathrm{K}_{3} \mathrm{PO}_{4}$ (3 equiv., $0.75 \mathrm{mmol}$ ), $\mathrm{H}_{2} \mathrm{O}$ (5 equiv., $1.25 \mathrm{mmol}$ ), DMI ( $1 \mathrm{~mL}$, $0.25 \mathrm{M}) .{ }^{b} \mathrm{NMR}$ conversion given as an average over 2 reactions.

Whilst we were able to synthesise a small range of substrates (Scheme 1, 3f, 3j, 3m) using 2 mol\% catalyst loading at $60{ }^{\circ} \mathrm{C}$, to accommodate a broader efficiency within the substrate classes, we found it was necessary to use a slightly higher catalyst loading of $4 \mathrm{~mol} \%$. With these conditions (Table 1, Entry 3), we were able to carry out the coupling of a range of aromatic $(\mathbf{3 b}, \mathbf{3 l})$ and vinyl $(\mathbf{3 g}, \mathbf{3 k})$ boronic acids and pinacol esters in high yield. Additionally, as is standard within the SM cross-coupling, electrophile variation was well tolerated (3c, 3e, 3m). Aromatics bearing electron-withdrawing and electron-donating groups were comparable in efficiency.

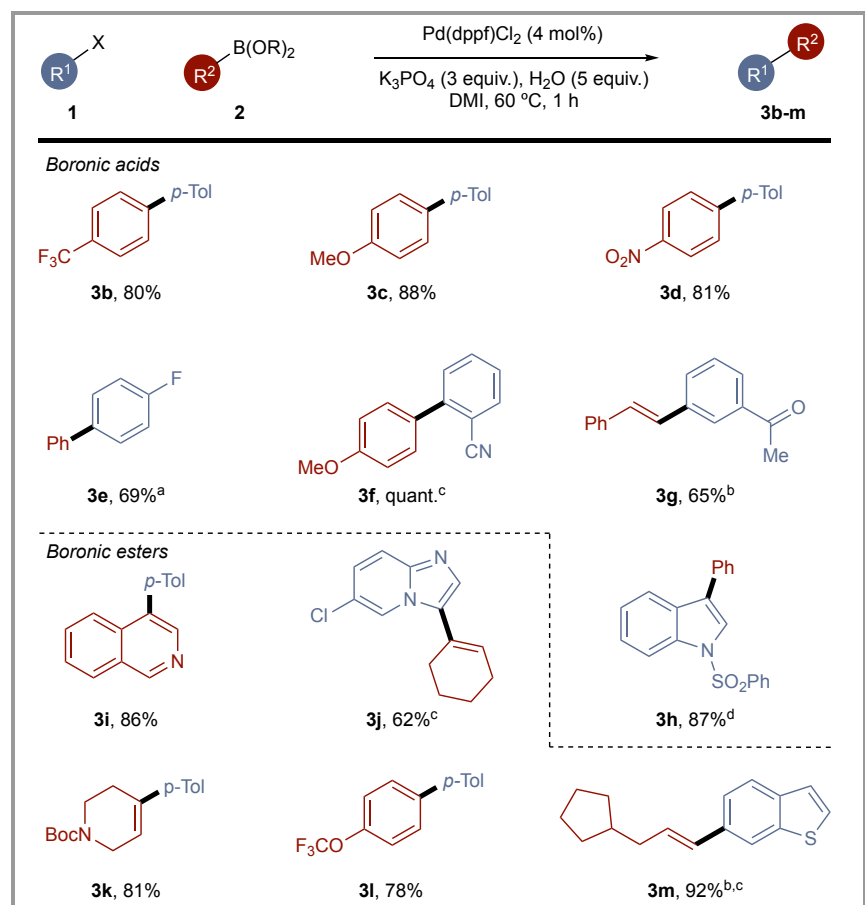

Scheme 1 DMI-based Suzuki Miyaura. Conditions: $\mathrm{Pd}(\mathrm{dppf}) \mathrm{Cl}_{2} \cdot \mathrm{CH}_{2} \mathrm{Cl}_{2}$ (4mol\%), organoboron (1 equiv., $0.25 \mathrm{mmol}$ ), aryl/vinyl (pseudo)halide (1 equiv., $0.25 \mathrm{mmol}$ ), $\mathrm{K}_{3} \mathrm{PO}_{4}$ (3 equiv., $0.75 \mathrm{mmol}$ ), $\mathrm{DMI}(1 \mathrm{~mL}), 1 \mathrm{~h}, 60^{\circ} \mathrm{C}$. (a) $\mathrm{X}=$ OTf, (b) $X=C l, P d(O A c) 2$ (4 mol\%), SPhos (8 mol\%), (c) Pd cat. (2 mol\%, 0.005 $\mathrm{mmol}),(\mathrm{d}) 1.2$ equiv. phenylboronic acid.

We next focused on the optimization of the MH crosscoupling (Table 2). Initial screening of the iodobenzene (4a) system using $\mathrm{Pd}\left(\mathrm{PPh}_{3}\right)_{2} \mathrm{Cl}_{2}$ catalyst revealed excellent reactivity at $80{ }^{\circ} \mathrm{C}$ with complete conversion to the desired product 6a in 8 hours (Table 2, Entry 1). We were subsequently able to reduce reaction time (Entry 2) but found that lower temperatures resulted in a loss of conversion (Entry 3). These conditions were then applied to the bromobenzene (4a') system with only trace amounts of product observed (Entry 4). However, by increasing the temperature, we found we were able to achieve high conversion over 24 hours (Entry 6).

Upon moving to investigate the scope of the reaction, we noticed that whilst coupling proceeded efficiently with electron-rich haloarenes, the coupling of 4-iodonitrobenzene 4f using $\mathrm{Pd}\left(\mathrm{PPh}_{3}\right)_{2} \mathrm{Cl}_{2}$ was unsuccessful (Entry 7). However, following a brief catalyst screen, $\mathrm{Pd}(\mathrm{dppf}) \mathrm{Cl}_{2}$ was found to deliver high reactivity and could facilitate the coupling in good isolated yield (Entry 9). 
Table 2 Reaction optimisation of Mizoroki-Heck conditions ${ }^{a}$

\begin{tabular}{|c|c|c|}
\hline X & Pd cat. (5 mol\%) & \\
\hline $\begin{array}{l}\mathbf{4 a}, X=I, R=H \\
\mathbf{4 a}, X=B r, R=H \\
\mathbf{4 f}, X=I, R=N_{2}\end{array}$ & $\begin{array}{l}\mathrm{Et}_{3} \mathrm{~N}(3 \text { equiv. }) \\
\mathrm{DMI}, \mathrm{T}^{\circ} \mathrm{C}, t \mathrm{~h}\end{array}$ & $6 a$ \\
\hline Entry & Reaction conditions & Conversion $(\%)^{b}$ \\
\hline 1 & $4 \mathrm{a}, \mathrm{Pd}\left(\mathrm{PPh}_{3}\right)_{2} \mathrm{Cl}_{2}, 80^{\circ} \mathrm{C}, 8 \mathrm{~h}$ & 100 \\
\hline 2 & $4 \mathrm{a}, \mathrm{Pd}\left(\mathrm{PPh}_{3}\right)_{2} \mathrm{Cl}_{2}, 80^{\circ} \mathrm{C}, 1 \mathrm{~h}$ & 100 \\
\hline 3 & 4a, $\mathrm{Pd}\left(\mathrm{PPh}_{3}\right)_{2} \mathrm{Cl}_{2}, 60^{\circ} \mathrm{C}, 1 \mathrm{~h}$ & 12 \\
\hline 4 & $4 a^{\prime}, \mathrm{Pd}\left(\mathrm{PPh}_{3}\right)_{2} \mathrm{Cl}_{2}, 80^{\circ} \mathrm{C}, 1 \mathrm{~h}$ & $<1$ \\
\hline 5 & $4 a^{\prime}, \mathrm{Pd}\left(\mathrm{PPh}_{3}\right)_{2} \mathrm{Cl}_{2}, 80^{\circ} \mathrm{C}, 24 \mathrm{~h}$ & 81 \\
\hline 6 & $4 a^{\prime}, \operatorname{Pd}\left(\mathrm{PPh}_{3}\right)_{2} \mathrm{Cl}_{2}, 115^{\circ} \mathrm{C}, 24 \mathrm{~h}$ & 98 \\
\hline 7 & $4 \mathrm{f}, \mathrm{Pd}\left(\mathrm{PPh}_{3}\right)_{2} \mathrm{Cl}_{2}, 80^{\circ} \mathrm{C}, 1 \mathrm{~h}$ & 0 \\
\hline 8 & $4 \mathrm{f}, \mathrm{Pd}\left(\mathrm{PPh}_{3}\right)_{4}, 80^{\circ} \mathrm{C}, 1 \mathrm{~h}$ & 0 \\
\hline 9 & $4 \mathrm{f}, \mathrm{Pd}(\mathrm{dppf}) \mathrm{Cl}_{2}, 80^{\circ} \mathrm{C}, 1 \mathrm{~h}$ & 85 \\
\hline
\end{tabular}

'adobenzene (4a), bromobenzene (4a') or 4-iodonitrobenzene (4f) (1 equiv., $0.25 \mathrm{mmol}$ ), $5 \mathrm{a}$ (2 equiv., $0.5 \mathrm{mmol}$ ), Pd cat. ( $5 \mathrm{~mol} \%, 0.013 \mathrm{mmol}$ ), $\mathrm{Et}_{3} \mathrm{~N}$ (3 equiv., $0.75 \mathrm{mmol}$ ), DMI $(1 \mathrm{~mL}, 0.25 \mathrm{M}) .{ }^{b} \mathrm{NMR}$ conversion given as an average over 2 reactions.

This catalyst system was effective when used to examine the substrate scope (Scheme 3). Good efficiency was observed in the coupling of both aryl iodides $(\mathbf{6 c}, \mathbf{6 e})$ and bromides $(\mathbf{6} \mathbf{j}$, 6h) and allowed for the coupling of electron-rich $(\mathbf{6 b}, \mathbf{6 e})$ and electron-deficient $(\mathbf{6 d}, \mathbf{6 g})$ arenes. Additionally, some variance of activated alkene $\mathbf{5}$ could be tolerated with the coupling of methyl vinyl ketone, phenyl vinyl ketone, and $\mathrm{N}, \mathrm{N}$-dimethylacrylamide undergoing successful coupling to furnish $6 \mathbf{i}, \mathbf{6 k}$, and $\mathbf{6 m}$, respectively.

Finally, we concluded our study on the use of DMI in Pdcatalysed bond forming reactions by investigating its application within the Sonogashira reaction. Using previously optimised conditions, ${ }^{31}$ we found that the coupling of 4-fluoroiodobenzene with phenylacetylene, to deliver 9a, proceeded smoothly and in high yield, based on this result further optimisation of the manifold was not deemed necessary.

Accordingly, these conditions were applied to a brief substrate scope (Scheme 4). A range of aryl iodides were coupled under mild conditions in 1 hour, with multiple substitution patterns tolerated around the aryl ring (9b, 9d, 9j). In addition, electron-deficient aryl bromides also demonstrated compatibility, with 5-bromo-2-nitropyridine undergoing conversion to $\mathbf{9 f}$ with an $84 \%$ isolated yield.

Similarly, a variety of groups were tolerated on the alkyne, with aryl (9h), vinyl (9l), and alkyl (9j) functionality coupling successfully. In addition, alkynes substituted with modifiable groups such as BMIDA and TIPS, furnished products $\mathbf{9 g}$ and $\mathbf{9 k}$ in high yields.

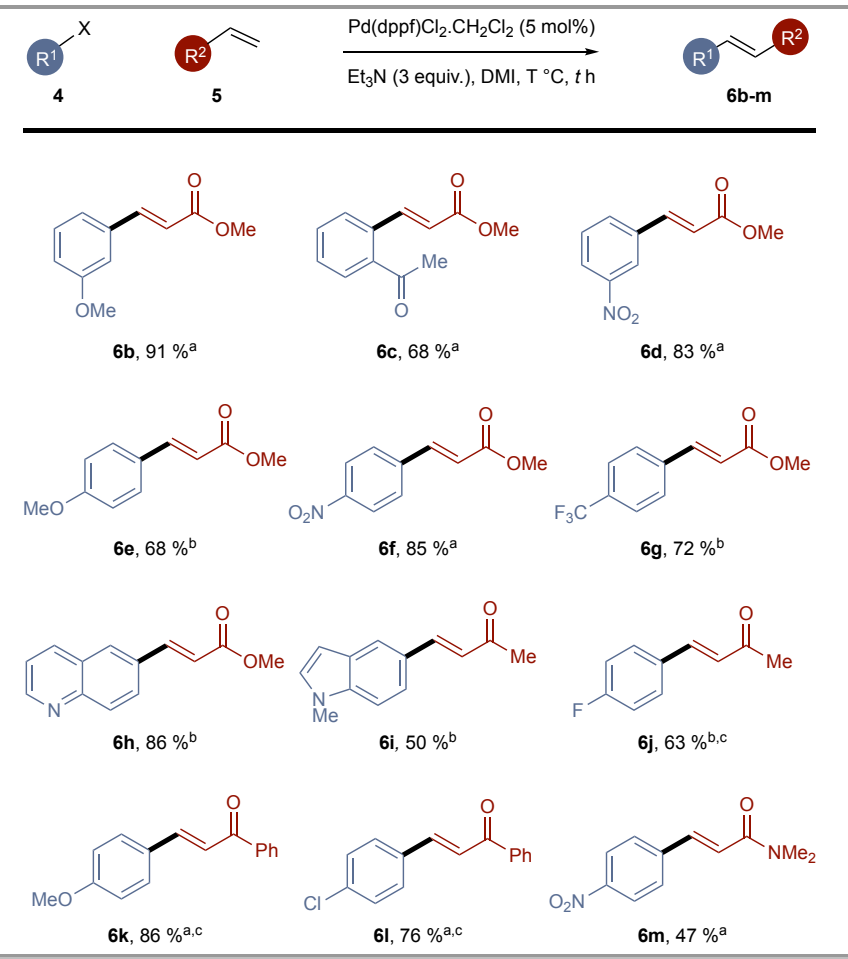

Scheme 3 DMI-based Mizoroki-Heck. Conditions: $\mathrm{Pd}(\mathrm{dppf}) \mathrm{Cl}_{2} \cdot \mathrm{CH}_{2} \mathrm{Cl}_{2}$ (5 mol\%, $0.013 \mathrm{mmol}$ ), aryl halide (1 equiv., $0.25 \mathrm{mmol}$ ), olefin (2 equiv., 0.5 $\mathrm{mmol}$ ), $\mathrm{Et}_{3} \mathrm{~N}$ (3 equiv., $0.75 \mathrm{mmol}$ ), DMI $\left(1 \mathrm{~mL}\right.$ ). (a) $\mathrm{X}=\mathrm{I}, 1 \mathrm{~h}, 80^{\circ} \mathrm{C},(\mathrm{b}) \mathrm{X}=\mathrm{Br}$, $24 \mathrm{~h}, 115^{\circ} \mathrm{C}$, (c) $\mathrm{K}_{3} \mathrm{PO}_{4}$ (3 equiv., $0.75 \mathrm{mmol}$ ) used as base.

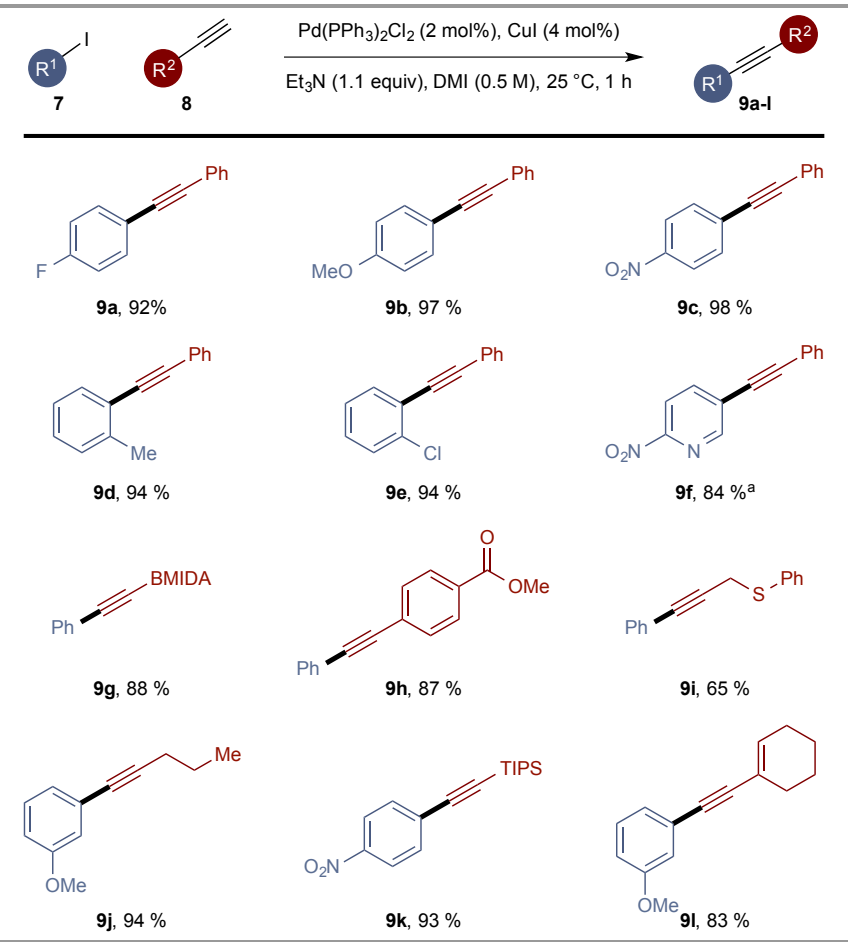

Scheme 4 DMI-based Sonogashira coupling. Conditions: $\mathrm{Pd}\left(\mathrm{PPh}_{3}\right)_{2} \mathrm{Cl}_{2} \quad(2$ mol\%), Cul (4 mol\%), aryl halide (1 equiv., $0.25 \mathrm{mmol}$ ), alkyne (1.05 equiv., $0.26 \mathrm{mmol}$ ), $\mathrm{Et}_{3} \mathrm{~N}$ (3 equiv., $0.75 \mathrm{mmol}$ ), DMI $\left(0.5 \mathrm{~mL}\right.$ ), $1 \mathrm{~h}, 25^{\circ} \mathrm{C}$. (a) 5 Bromo-2-nitropyridine as coupling partner.

With regards to practicality, DMI has a high boiling point and issues may be expected in terms of its removal from products. In our hands, we found that standard aqueous washing procedures were sufficient to remove the majority of DMI from the crude products, with any remaining traces 
removed during purification by column chromatography. In this context, DMI can be viewed as having similar purification considerations as would be typically required when using DMF or NMP.

In summary, we have shown the compatibility of the biobased solvent DMI as an alternative to solvents of concern, within Pd-catalyzed bond forming processes. Each transformation (SM, MH, and Sonogashira), displays excellent generality within the investigation of scope and facilitated the preparation of a range of small molecules. No potential limitations (such as sensitivity towards reagents) were identified throughout this study, and the nonmutagenic and non-toxic attributes, 53 in addition to the renewable source of this solvent, make it an attractive alternative to solvents of concern such as DMF and THF.

\section{Funding Information}

We thank the University of Strathclyde for a PhD studentship (KLW) and Merck KGaA, Darmstadt, Germany, for financial and material support.

\section{Acknowledgment}

We thank GSK for provision of dimethyl isosorbide, and the EPSRC UK National Mass Spectrometry Facility at Swansea University for analyses.

\section{Supporting Information}

YES (this text will be updated with links prior to publication)

\section{Primary Data}

NO (this text will be deleted prior to publication)

\section{References and Notes}

(1) Jessop, P. G. Green Chem., 2011, 13, 1391-1398.

(2) Clark, J. H.; Tavener, S. J. Org. Process Res. Dev., 2007, 11, 149-155.

(3) Welton, T. Proc. R. Soc. A, 2015, 471, 1-26.

(4) Dunn, P. J. Chem. Soc. Rev., 2012, 41, 1452-1461.

(5) Roschangar, F.; Colberg, J.; Dunn, P. J.; Gallou, F.; Hayler, J. D.; Koenig, S. G.; Kopach, M. E.; Leahy, D. K.; Mergelsberg, I.; Tucker, J. L.; Sheldon, R. A.; Senanayake, C. H. Green Chem., 2016, 19, $281-$ 285.

(6) Constable, D. J. C.; Dunn, P. J.; Hayler, J. D.; Humphrey, G. R.; Leazer, J. L.; Linderman, R. J.; Lorenz, K.; Manley, J.; Pearlman, B. A.; Wells, A.; Zaks, A.; Zhang, T. Y. Green Chem., 2007, 9, 411-420.

(7) Tobiszewski, M.; Namieśnik, J.; Pena-Pereira, F. Green Chem., 2017, 19, 1034-1042.

(8) Alder, C. M.; Hayler, J. D.; Henderson, R. K.; Redman, A. M.; Shukla, L.; Shuster, L. E.; Sneddon, H. F. Green Chem., 2016, 18, 38793890 .

(9) Byrne, F. P.; Jin, S.; Paggiola, G.; Petchey, T. H. M.; Clark, J. H.; Farmer, T. J.; Hunt, A. J.; McElroy, C. R.; Sherwood, J. Sustain. Chem. Process, 2016, 4:7.

(10) Diorazio, L. J.; Hose, D. R. J.; Adlington, N. K. Org. Process Res. Dev., 2016, 20, 760-773.

(11) Eastman, H. E.; Jamieson, C.; Watson, A. J. B. Aldrichimica Acta., 2015, 48, 51-55

(12) Prat, D.; Wells, A.; Hayler, J.; Sneddon, H. F.; McElroy, C. R.; AbouShehada, S.; Dunn, P. J. Green Chem., 2015, 18, 288-296.

(13) Skowerski, K.; Białecki, J.; Tracz, A.; Olszewski, T. K. Green Chem., 2014, 16, 1125-1130.
(14) eChemPortal - Home, http://www.echemportal.org/echemportal/substancesearch/pag e.action?pageID=0, (accessed October 2017).

(15) Candidate List of substances of very high concern for authorisation - ECHA, https://echa.europa.eu/candidate-listtable, (accessed October 2017).

(16) Horváth, I. T. Green Chem., 2008, 10, 1024-1028.

(17) Spear, S. K.; Griffin, S. T.; Granger, K. S.; Huddleston, J. G.; Rogers, R. D. Green Chem., 2007, 9, 1008-1015.

(18) Gu, Y.; Jérôme, F. Green Chem., 2010, 12, 1127-1138.

(19) Pace, V.; Hoyos, P.; Castoldi, L.; Dominguez de Maria, P.; Alecantara, A. R. ChemSusChem, 2012, 5, 1369-1379.

(20) Lomba, L.; Giner, B.; Bandrés, I.; Lafuente, C.; Pino, R. Green Chem., 2011, 13, 2062-2070.

(21) Pereira, C. S. M.; Silva, V. M. T. M.; Rodrigues, A. E. Green Chem., 2011, 13, 2658-2671.

(22) Alonso, D. M.; Wettstein, S. G.; Dumesic, J. A. Green Chem., 2013, 15, 584-595.

(23) Byrne, F.; Forier, B.; Bossaert, G.; Hoebers, C.; Farmer, T. J.; Clark, J. H.; Hunt, A. J. Green Chem., 2017, 19, 3671-3678.

(24) Ilgen, F.; König, B. Green Chem., 2009, 11, 848-854.

(25) Imperato, G.; Vasold, R.; König, B. Adv. Synth. Catal., 2006, 348, 2243-2247.

(26) Pongrácz, P.; Kollár, L.; Mika, L. T. Green Chem., 2016, 18, 842847.

(27) Ismalaj, E.; Strappaveccia, G.; Ballerini, E.; Elisei, F.; Piermatti, O.; Gelman, D.; Vaccaro, L. ACS Sus. Chem. Eng., 2014, 2, 2461-2464.

(28) Strappaveccia, G.; Luciani, L.; Bartollini, E.; Marrocchi, A.; Pizzo, F.; Vaccaro, L. Green Chem., 2015, 17, 1071-1076.

(29) Rasina, D.; Kahler-Quesada, A.; Ziarelli, S.; Warratz, S.; Cao, H.; Santoro, S.; Ackermann, L.; Vaccaro, L. Green Chem., 2016, 18, 5025-5030.

(30) Strappaveccia, G.; Ismalaj, E.; Petrucci, C.; Lanari, D.; Marrocchi, A.; Drees, M.; Facchetti, A.; Vaccaro, L. Green Chem., 2014, 17, 365372.

(31) Wilson, K. L.; Kennedy, A. R.; Murray, J.; Greatrex, B.; Jamieson, C.; Watson, A. J. B. Beilstein J. Org. Chem., 2016, 12, 2005-2011.

(32) Wilson, K. L.; Murray, J.; Jamieson, C.; Watson, A. J. B. Synlett, 2018, 29, 650-654.

(33) Wilson, K. L.; Murray, J.; Jamieson, C.; Watson, A. J. B. Org. Biomol. Chem., 2018, 16, 2851-2854.

(34) Camp, J. E. ChemSusChem, 2018, DOI: 10.1002/cssc.201801420

(35) Aricò, F.; Tundo, P. Beilstein J. Org. Chem., 2016, 12, 2256-2266.

(36) Aricò, F.; Aldoshin, A.; Tundo, P. ChemSusChem, 2016, 10, 53-57.

(37) Desai, N. P.; Tao, C.; Yang, A.; Beal-Grim, B.; De, T.; Soon-Shiong, P. Compositions and methods for the preparation and administration of poorly water soluble drugs, U.S. Patent 0171687, July 17, 2008.

(38) Luzzi, L. A.; Ma, J. K. H. Dimethyl isosorbide in liquid formulation of asprin, U.S. Patent 4228162, Oct. 14, 1980.

(39) Salavagione, H. J.; Sherwood, J.; De Bruyn, M.; Budarin, V. L.; Ellis, G. K.; Clark, J. H.; Shuttleworth, P. S. Green Chem., 2017, 19, 25502560.

(40) Lawreson, S.; North, M.; Peigneguy, F.; Routledge, A. Green Chem., 2017, 19, 952-962.

(41) Jad, Y. E.; Govender, T.; Kruger, H. G.; El-Faham, A.; de la Torre, B. G.; Albericio, F. Org. Process Res. Dev., 2017, 21, 365-369.

(42) King, A. O.; Yasuda, N. Palladium-Catalyzed Cross-Coupling Reactions in the Synthesis of Pharmaceuticals, Springer, Heidelberg, 2004.

(43) Nicolaou, K. C.; Bulger, P. G.; Sarlah, D. Angew. Chem. Int. Ed., 2005, 44, 4442-4489. 
(44) Roughley, S. D.; Jordan, A. M. J. Med. Chem., 2011, 54, 3451-3479.

(45) Brown, D. G.; Boström, J. J. Med. Chem., 2016, 59, 4443-4458.

(46) Blakemore, D. C.; Doyle, P. M.; Fobian, Y. M. Synthetic Methods in Drug Discovery, Royal Society of Chemistry, Cambridge, 2016.

(47) Ohe, T.; Miyaura, N.; Suzuki, A. J. Org. Chem., 1993, 58, 2201-2208.

(48) Miyaura, N.; Suzuki, A. Chem. Rev., 1995, 95, 2457-2483.

(49) Oestreich, M. The Mizoroki-Heck Reaction, Wiley, Chichester, 2009.

(50) Chinchilla, R.; Nájera, C. Chem. Rev. 2007, 107, 874-922.

(51) Sigma Aldrich Cross-Coupling Reaction Manual: Desk Reference, https://www.sigmaaldrich.com/content/dam/sigmaaldrich/docs/Aldrich/Method/1/83784-Cross-CouplingSelection-Brochure.pdf (accessed August 2018).

(52) Fyfe, J. W. B.; Valverde, E.; Seath, C. P.; Kennedy, A. R.; Redmond, J. M.; Anderson, N. A.; Watson, A. J. B. Chem. Eur. J., 2015, 21, 89518964.

(53) Australian NICNAS: Regulatory Information on DMI https://www.nicnas.gov.au/search?query=arlasolve+dmi\&collect ion=nicnas-meta (accessed August 2018).

(54) General Procedure for Suzuki-Miyaura Coupling in DMI To an oven dried $5 \mathrm{~mL}$ microwave vessel was added $\mathrm{Pd}(\mathrm{dppf}) \mathrm{Cl}_{2} \cdot \mathrm{CH}_{2} \mathrm{Cl}_{2} \quad(4 \mathrm{~mol} \%)$, aryl halide/pseudohalide (1 equiv.), organoboron (1 equiv.), and $\mathrm{K}_{3} \mathrm{PO}_{4}$ (3 equiv.). The vessel was then capped and purged with $\mathrm{N}_{2}$ before addition of DMI ( 1 $\mathrm{mL}, 0.25 \mathrm{M}$ ), and $\mathrm{H}_{2} \mathrm{O}$ (5 equiv.). The reaction mixture was heated to $60{ }^{\circ} \mathrm{C}$ and maintained at this temperature with stirring for $1 \mathrm{~h}$ before the vessel was vented, and decapped. The solution was then diluted with EtOAc $(10 \mathrm{~mL})$, and washed with water $(2 \times 20$ $\mathrm{mL})$ and brine $(2 \times 20 \mathrm{~mL})$. The organics were then passed through a hydrophobic frit and concentrated under reduced pressure to give a residue, which was purified by flash chromatography (silica gel) to afford the product.

4-Phenyltoluene (3a). Prepared according to the General Procedure using $\mathrm{Pd}(\mathrm{dppf}) \mathrm{Cl}_{2} \cdot \mathrm{CH}_{2} \mathrm{Cl}_{2}$ (8.2 $\mathrm{mg}, 0.01 \mathrm{mmol}, 4 \mathrm{~mol} \%$ ), bromotoluene 1a (43 $\mathrm{mg}, 0.25 \mathrm{mmol}, 1$ equiv.), phenylboronic acid 2 a (30.5 mg, $0.25 \mathrm{mmol}, 1$ equiv.), $\mathrm{K}_{3} \mathrm{PO}_{4}$ (159 mg, 0.75 mmol, 3 equiv.), DMI ( $1 \mathrm{~mL}, 0.25 \mathrm{M})$, and $\mathrm{H}_{2} \mathrm{O}(23 \mu \mathrm{L}, 1.25 \mathrm{mmol}$, 5 equiv.). After $1 \mathrm{~h}$, the reaction mixture was subjected to the purification method outlined in the General Procedure (silica gel, $0-5 \%$ EtOAc in petroleum ether) to afford the title compound as a white solid (42.9 mg, quant.). ${ }^{1} \mathrm{H}$ NMR $\left(\mathrm{CDCl}_{3}, 400 \mathrm{MHz}\right): \delta 7.62$ (dd, $J=8.3,1.2 \mathrm{~Hz}, 2 \mathrm{H}), 7.53(\mathrm{~d}, J=8.1 \mathrm{~Hz}, 2 \mathrm{H}), 7.46(\mathrm{t}, J=7.6 \mathrm{~Hz}$, 2H), $7.38-7.33$ (m, 1H), 7.29 (d, $J=7.9 \mathrm{~Hz}, 2 \mathrm{H}), 2.43(\mathrm{~s}, 3 \mathrm{H}) .{ }^{13} \mathrm{C}$ $\mathrm{NMR}\left(\mathrm{CDCl}_{3}, 101 \mathrm{MHz}\right): \delta 141.3,138.5,137.2,129.6,128.9,127.1$, 21.2.

(55) General Procedure for Mizoroki-Heck Coupling in DMI To an oven dried $5 \mathrm{~mL}$ microwave vessel was added $\mathrm{Pd}(\mathrm{dppf}) \mathrm{Cl}_{2} \cdot \mathrm{CH}_{2} \mathrm{Cl}_{2}(5 \mathrm{~mol} \%)$ and aryl halide (1 equiv.). The vessel was capped and purged with $\mathrm{N}_{2}$ before addition of DMI (1
$\mathrm{mL}, 0.25 \mathrm{M}$ ), alkene coupling partner (2 equiv.), and $\mathrm{Et}_{3} \mathrm{~N}$ (3 equiv.). The reaction mixture was heated to either $80{ }^{\circ} \mathrm{C}(\mathrm{X}=\mathrm{I})$ or $115{ }^{\circ} \mathrm{C}(\mathrm{X}=\mathrm{Br})$ and maintained at this temperature with stirring for $1 \mathrm{~h}(\mathrm{X}=\mathrm{I})$ or $24 \mathrm{~h}(\mathrm{X}=\mathrm{Br})$ before the vessel was vented, and decapped. The solution was then diluted with EtOAc $(10 \mathrm{~mL})$, and washed with water $(2 \times 20 \mathrm{~mL})$ and brine $(2 \times 20 \mathrm{~mL})$. The organics were then passed through a hydrophobic frit and concentrated under reduced pressure to give a residue, which was purified by flash chromatography (silica gel) to afford the product.

Methyl cinnamate (6a). Prepared according to the General Procedure using $\mathrm{Pd}(\mathrm{dppf}) \mathrm{Cl}_{2} \cdot \mathrm{CH}_{2} \mathrm{Cl}_{2}(10.2 \mathrm{mg}, 0.013 \mathrm{mmol}, 5$ mol\%), iodobenzene $4 \mathrm{a}$ ( $28 \mu \mathrm{L}, 0.25 \mathrm{mmol}, 1$ equiv.), methyl acrylate $5 \mathbf{a}\left(45 \mu \mathrm{L}, 0.5 \mathrm{mmol}, 2\right.$ equiv.), $\mathrm{Et}_{3} \mathrm{~N}(105 \mu \mathrm{L}, 0.75 \mathrm{mmol}$, 3 equiv.), DMI ( $1 \mathrm{~mL}, 0.25 \mathrm{M})$. After $1 \mathrm{~h}$, the reaction mixture was subjected to the purification method outlined in the General Procedure (silica gel, 0-5\% EtOAc in petroleum ether) to afford the title compound as a white solid (40 mg, $99 \%$ ). ${ }^{1} \mathrm{H}$ NMR $\left(\mathrm{CDCl}_{3}, 500 \mathrm{MHz}\right): \delta 7.70(\mathrm{~d}, J=16.0 \mathrm{~Hz}, 1 \mathrm{H}), 7.53(\mathrm{dd}, J=6.6,2.8$ $\mathrm{Hz}, 2 \mathrm{H}), 7.41-7.37(\mathrm{~m}, 3 \mathrm{H}), 6.45(\mathrm{~d}, J=16.0 \mathrm{~Hz}, 1 \mathrm{H}), 3.81(\mathrm{~s}, 3 \mathrm{H})$. ${ }^{13} \mathrm{C}$ NMR $\left(\mathrm{CDCl}_{3}, 101 \mathrm{MHz}\right): \delta 167.6,145.0,134.6,130.4,129.0$, 128.2, 117.9, 51.8 .

(56) General Procedure for Sonogashira Coupling in DMI

To an oven dried $5 \mathrm{~mL}$ microwave vessel was added $\mathrm{Pd}\left(\mathrm{PPh}_{3}\right)_{2} \mathrm{Cl}_{2}$ (2 mol\%), aryl halide (1 equiv.), and alkyne coupling partner (1.05 equiv.). The vessel was capped and purged with $\mathrm{N}_{2}$ before addition of DMI $(0.5 \mathrm{~mL}, 0.5 \mathrm{M})$, and $\mathrm{Et}_{3} \mathrm{~N}$ (1.1 equiv.). The reaction mixture was maintained at room temperature $\left(25^{\circ} \mathrm{C}\right)$ with stirring for $1 \mathrm{~h}$ before the vessel was vented, and decapped. The solution was then diluted with EtOAc $(10 \mathrm{~mL})$, and washed with water $(2 \times 20 \mathrm{~mL})$ and brine $(2 \times 20 \mathrm{~mL})$. The organics were then passed through a hydrophobic frit and concentrated under reduced pressure to give a residue, which was purified by flash chromatography (silica gel) to afford the product.

1-Fluoro-4-(phenylethynyl)benzene (9a). Prepared according to the General Procedure using $\mathrm{Pd}\left(\mathrm{PPh}_{3}\right)_{2} \mathrm{Cl}_{2}(3.5 \mathrm{mg}, 0.005 \mathrm{mmol}$, 2 mol\%), 4-fluoroiodobenzene 7 a (29 $\mu \mathrm{L}, 0.25 \mathrm{mmol}, 1$ equiv.), phenylacetylene 8a ( $29 \mu \mathrm{L}, 0.26 \mathrm{mmol}, 1.05$ equiv.), $\mathrm{Et}_{3} \mathrm{~N}$ (38 $\mu \mathrm{L}$, $0.28 \mathrm{mmol}, 1.1$ equiv.), DMI ( $0.5 \mathrm{~mL}, 0.5 \mathrm{M})$. After $1 \mathrm{~h}$, the reaction mixture was subjected to the purification method outlined in the General Procedure (silica gel, 0-5\% EtOAc in petroleum ether) to afford the title compound as a white solid (45 mg, $92 \%$ ). ${ }^{1} \mathrm{H}$ NMR $\left(\mathrm{CDCl}_{3}, 500 \mathrm{MHz}\right): \delta 7.55-7.50(\mathrm{~m}, 4 \mathrm{H}), 7.38-7.33(\mathrm{~m}, 3 \mathrm{H}), 7.05$ $(\mathrm{t}, J=8.7 \mathrm{~Hz}, 2 \mathrm{H}) \cdot{ }^{13} \mathrm{C} \mathrm{NMR}\left(\mathrm{CDCl}_{3}, 126 \mathrm{MHz}\right): \delta 162.7\left(\mathrm{~d},{ }^{1} J=\right.$ $249.6 \mathrm{~Hz}$ ), 133.6 (d, $3 J=8.2 \mathrm{~Hz}$ ), 131.7, 128.5, 128.5, 123.3, 119.5 $\left(\mathrm{d},{ }^{4} J=3.4 \mathrm{~Hz}\right), 115.8\left(\mathrm{~d},{ }^{2} J=22.4 \mathrm{~Hz}\right), 89.2,88.4 .{ }^{19} \mathrm{~F} \mathrm{NMR}\left(\mathrm{CDCl}_{3}\right.$, $471 \mathrm{MHz}$,) $\delta-110.98$. 